\title{
РЕГУЛИРОВАНИЕ
}

\section{ТЕЛЕКОММУНИКАЦИИ в условиях кризиса COVID-19}

Б.Ластович, независимый эксперт / blastovich@mail.ru

DOI: 10.22184/2070-8963.2020.91.6.58.62

Обсуждаются итоги совещания по вопросам развития информационно-коммуникационных технологий и связи, проведенного Президентом России Владимиром Путиным 10 июня 2020 года, которые имеют большое значение для отрасли связи. Выражается надежда, что результатом их проработки станут решения, эффективные для развития цифровой инфраструктуры страны и успешного послекризисного восстановления.

Более полутора столетий телекоммуникации - электрическая, затем электронная связь - являются одной из систем жизнеобеспечения, неотъемлемой составляющей базовой инфраструктуры стран и мира. Со времени своего появления сети электросвязи имеют глобальный характер, всеми государствами развиваются согласованно, на единых стандартах, совместимых технологиях, правилах взаимодействия и взаиморасчетов.

В конце 20 века на смену телефонным и телеграфным сетям с прямым соединением абонентов пришли широкополосные (высокоскоростные) цифровые сети нового поколения на технологиях коммутации пакетов данных с использованием IP-протоколов. Эти конвергентные сети предоставляют любому пользователю в любом месте возможность получения широкого перечня коммуникационных услуг и любого контента, обеспечивают взаимодействие машин, организацию программно-управляемых систем в любой сфере деятельности.

Сегодня конвергентные сети электросвязи нового поколения уже стали привычными и необходимыми в нашей жизни так же, как сети энерго- и водоснабжения, которые, заметим, сегодня тоже не могут работать без средств электросвязи. Возможность широкополосного доступа (ШПД) к сетям, а следовательно, и к благам интернета уже создана для $92 \%$ населения планеты. В нашей стране, согласно данным Минцифры России, к началу 2020 года количество договоров на ШПД превышало 150 млн.

Никогда прежде эти сети и реализуемые с их использованием услуги и множество цифровых решений не были так важны для нашего здоровья и безопасности, а также для поддержания работоспособности экономики и общества, как в условиях глобального кризиса, вызванного пандемией COVID-19. Причиной тому все более широкое и ответственное их применение, поскольку информационно-коммуникационные технологии (ИКТ) сегодня используются повсеместно, практически во всех областях жизни и деятельности. Пандемия обострила спрос на цифровые коммуникации, а следовательно, и требования к сетям.

Чрезвычайные условия диктуют необходимость решения новых задач, связанных с реализацией государствами антикризисных мер: самоизоляцией граждан, рассредоточением офисов, дистанцион ${ }^{-}$ ным обучением и др. К примеру, организация удаленной работы сотрудников организаций, дистанционное обучение в школах и вузах возможны только при наличии развитой и надежной цифровой инфраструктуры, основой которой являются широкополосные сети электросвязи.

Новые требования к телекоммуникациям в условиях развивающейся пандемии обусловили необходимость выработки единых для всех стран рекомендаций на базе экспертных оценок и передового международного опыта. Комиссия по широкополосной связи в интересах устойчивого развития (созданная в 2010 году в структуре ООН) провела в апреле 2020 года экстренное заседание с участием специализирован ных организаций ООН (МСЭ- Международного союза электросвязи, ЮНЕСКО, ЮНИСЕФ, Всемирный банк) и более 100 компетентных руководителей и специалистов из разных государств мира, на котором была принята Программа действий по поддержке 
цифровых сетей, определившая неотложные меры, рекомендованные правительствам, отраслям, гражданскому обществу с тем, чтобы усилить коллективные ответные меры по преодолению кризиса, вызванного распространением инфекции COVID-19.

Программа рассматривается как платформа для обмена инициативами, принятия новых обязательств и содействия сотрудничеству и партнерству для государств-членов ООН и ее организаций. Укрепление и масштабирование сотрудничества в области широкополосной связи призвано помочь выработке и реализации коллективного ответа на COVID-19 и заложить основу для более быстрого восстановления всех сфер, затронутых кризисом.

Чтобы уменьшить воздействие пандемии и облегчить неблагоприятные последствия для экономики и общества, а также для обеспечения более быстрого восстановления за счет сведения к минимуму социальных и экономических последствий COVID-19, готовности к возможным в будущем глобальным вызовам, программа рекомендует уделить основное внимание трем аспектам:

1. Устойчивые подключения. Необходимо поддерживать надежную, устойчивую и безопасную цифровую инфраструктуру и адаптировать ее к потребностям всех групп пользователей с учетом запросов, возникающих в ходе применения антикризисных мер, включая карантинные, службы экстренного реагирования, логистику и др. Для этого, в частности, рекомендовано определить приоритеты для подключений к важнейшим государственным функциям, жизненно важным службам и стратегическим точкам подключения (таким как больницы, аптеки, центры экстренной помощи, транспортные узлы...), увеличить пропускную способность сетей и направлений на основе постоянного мониторинга с учетом роста объемов трафика, вызванного антикризисными мерами, принять ряд мер по укреплению устойчивости, по увеличению скорости и надежности широкополосного доступа к сетям и услугам для пользователей;

2. Доступность подключений для всех. Рекомендовано повышение ценовой доступности ШПД, услуг и устройств для обеспечения непрерывности бизнеса, обеспечение бесперебойного доступа к сетям, сервисам и информационным ресурсам для поддержки населения во время самоизоляции, а также для решения финансовых трудностей и экономических проблем. Для этого рекомендованы такие меры, как снижение тарифов и скидки на трафик, предоставление пользователям необходимых устройств в критических случаях, организация и поддержка альтернативных моделей финансирования для решений с бесплатным доступом;

3. Безопасное использование онлайн-сервисов. Необходимо поддерживать безопасное использование онлайн-сервисов всеми, особенно детьми и уязвимыми группами населения, способствовать доверию и безопасности при использовании данных, уважать право на неприкосновенность частной жизни. А также обеспечивать безопасный обмен цифровым контентом для поддержки электронных образования, здравоохранения, электронных финансовых услуг и мобильных платежей, цифрового сельского хозяйства, а также платформ электронного правительства. Также отмечена необходимость предоставлять населению научно обоснованную информацию о COVID-19, продвигать медийную и информационную грамотность для понимания опасностей распространения ложных фактов о вирусе.

Программа содержит развернутые рекомендации по немедленным действиям, которые прямо адресованы национальным регулирующим органам, организациям в сфере телекоммуникаций, науки, профильных некоммерческих организаций.

Сведений о какой-либо реакции нашего отраслевого регулятора на программу действий Комиссии ООН автору обнаружить не удалось, но следует отметить, что ряд мер, предпринимаемых в России, соответствует рекомендованным Программой.

Российская Федерация едва ли не единственная страна в мире, в которой национальным регулятором в сфере электросвязи/ИКТ все еще, со времен госмонополии на средства связи, остается правительственный орган, ныне носящий название Министерство цифрового развития, связи и массовых коммуникаций. В большинстве других стран в условиях рынка эти функции давно выполняют независимые, в том числе и от исполнительной власти, регулирующие органы.

На официальном сайте министерства в состав направления деятельности "телекоммуникации" включено новое "направление": "Меры по борьбе с коронавирусной инфекцией COVID-19". Однако ничего связанного с электросвязью в этой чрезвычайной ситуации, с инфекцией, как таковой, по состоянию на сентябрь 2020 года, там не было. Имелись лишь "Полезные ссылки портала Госуслуг" и список Telegram-каналов с информацией о рейсах, на которых россияне могут вернуться на Родину. 
И это не удивляет, так как в нашей стране регулирование развития сектора электросвязи/ИКТ в интересах государства, экономики и социума в условиях рынка до настоящего времени не налажено. Не определена политика, не выработаны стратегия и планы развития пространственной основы циф ровой инфраструктуры страны - функционально единой национальной широкополосной сети электросвязи, как это в свое время было сделано и реализовано в $86 \%$ стран мира. Рекомендации МСЭ и "Большой двадцатки" (G20), членом которых является Россия, ежегодных Глобальных симпозиумов для регуляторных органов, вырабатывающих согласованные решения на основе передового опыта, по мнению автора, в должной степени не учитываются.

Между тем, в России в роли современной сети связи общего пользования выступает стихийно сложившийся конгломерат из более 2 тыс. частных коммерческих сетей, объединенных условиями взаимных договоров о присоединении для обмена трафиком. Отсутствие целевого регулирования развития и взаимодействия этих сетей в составе составляющих функционально единой национальной сети привело к невозможности реализации ряда инфраструктурных функций, таких как обеспечение и поддержание необходимых параметров, включая качество, управление единой сетью, в том числе и кризисное. При том, что приоритетное развитие национальных сетей на технологиях нового поколения, строгое поддержание их требуемых технических, технологических и иных параметров - одно из обязательных условий успешных цифровых преобразований, обеспечения минимальных системных рисков, которые могут проявится во всех сферах использования цифровой инфраструктуры.

Судя по публикуемым материалам и действиям регулятора, его чиновники все эти годы уделяли повышенное внимание бизнесу в сфере информационных технологий (ИТ), отделяя их от коммуникационной составляющей ИКТ без учета того факта, что их распространение и использование прямо зависят от развития и состояния сетей электросвязи. В отличие от ИТ-бизнеса, и спустя четверть века после становления рынка услуг связи в России регулирование в сфере телекоммуникаций все еще осуществляется административными, командными методами при отсут ствии необходимого в условиях рынка соблюдения баланса интересов государства, бизнеса и социума. K тому же, впервые за 150 лет существования электросвязи к выработке системных решений, к подготовке нормативно-правовой базы практически не привлекается отечественная отраслевая наука.

Благодаря частному капиталу и конкурентному рынку, наличию единых мировых стандартов, оборудования и готовым технологическим решениям зарубежных вендоров широкополосные сети в нашей стране строились беспрецедентно быстро, но - в коммерческих интересах операторов, когда развитие всецело определяется спросом.

Ценовая доступность ШПД у нас одна из самых высоких в мире, как и уровень дистанционного предоставления госуслуг, развития систем видеонаблюдения. А Москва - в числе лидеров в реализации цифровых решений по созданию умного города, в сферах образования и здравоохранения. По дан ным АНО "Цифровая экономика", число физических лиц - пользователей интернетом, в 2019 году превысило 94 млн, широкополосный доступ к благам ИКТ имеется у 76\% домашних хозяйств.

Как видим, наша страна находится вполне в русле мировых тенденций цифровых преобразований. В ежегодно публикуемых МСЭ отчетах по сводному индексу применения ИКТ Россия устойчиво занимает место в четвертой десятке стран мира; по международному индексу цифровой готовности Cisco - на 45-й позиции; по индексу цифровой конкурентоспособности Международного института развития (IMD) - на 38-й.

Эти данные свидетельствуют так же и о том, что государственные органы, экономика и население Российской Федерации зависят от бесперебойной и качественной работы своей цифровой инфра структуры в не меньшей степени, чем в других странах. Опыт работы в условиях пандемии подтвердил это.

Однако этот опыт и приведенный выше краткий анализ ситуации в регулировании и развитии цифровой инфраструктуры Российской Федерации ставят под сомнение ее реальные возможности обеспечения необходимых базовых качеств, определяемых уровнем развития и параметрами коммуникационной основы - таких как надежность, устойчивость, пропускная способность, качество предоставляемых потребителям коммуникаций.

Наблюдения за работой в период самоизоляции некоторых популярных в Москве радиостанций при переходе со студийных передач на онлайновые подключения удаленных участников с использованием мессенджеров показали, что едва ли не каждое второе из них имело недопустимо низкое качество: пропадания, помехи, искажения даже при соединениях внутри города. Часто по ходу передачи приходилось отказываться от видеообмена 
с удаленными участниками, оставляя только VoIP, а то и вовсе переходить на телефонную связь, что свидетельствует о недостаточной пропускной способности линий доступа.

Вероятно, из-за возросшего общего трафика (недостаточной пропускной способности сетей) испытывали неудобства с пропаданиями звука слушатели радиостанций, вещающих через интернет. Эти же проблемы отмечали и участники дистанционного обучения, удаленной работы. Отметим, что речь идет о частных онлайн-подключениях, голосовой связи и трансляциях звуковых программ, не критичных к конечному, сквозному качеству обмена данными.

Иное дело - обеспечение этой же сетью потребностей цифровой экономики, работы государственных платформ и систем управления, массового обслуживания, связи между машинами и программируемыми системами. Использование инфраструктуры такого качества для указанных целей влечет за собой недопустимо высокие риски, которые могут проявляться во всех сферах использования цифровых решений. Примером тому недавние сбои инфраструктурного характера в работе Единого государственного реестра недвижимости "Росреестр", затронувшие в нескольких регионах тысячи потребителей его услуг и участников сделок с недвижимостью.

Возможности объективной оценки качества работы сети общего пользования, цифровой инфраструктуры в условиях пандемии, как и в обычное время, не имеются в виду отсутствия достоверной статистики и механизмов ее получения: обследований, мониторинга и измерений в целом по сети.

Публикуемая регулятором ведомственная статистика на основании данных самих операторов не позволяет оценить состояние и возможности нашей цифровой инфраструктуры, ее коммуникационной основы, в том числе и в решении проблем, связанных с ЧС. Опубликованные на официальном сайте Минцифры данные за 2019 год составлены по лекалам прошлого века, где главное - телефонная связь (местная, зоновая и т.д.), присутствует даже неведомая сегодня потребителям "документальная связь". Сведений о широкополосных сетях нет вовсе, количество "абонентов" ШПД учтено только для стационарных линий, а для линий подвижной связи сохранена все та же "телефонная плотность", несмотря на то, что широкополосных подключений на сотовых сетях в семь раз больше.

Между тем, актуальная и достоверная статистика - основа организации действенного, оперативного, необходимого для реализации потенциала цифровых преобразований регулирования, планов и программ развития, ориентированных на конечные результаты. Это в очередной раз подчеркнуто в "Руководящих указаниях для национальных регуляторов на примерах передового опыта" Глобального симпозиума для регуляторных органов ГСР-2019. Факты свидетельствуют, что в нашей стране такая основа отсутствует.

Вместе с тем нельзя отрицать, что на высших уровнях власти существует понимание значимости цифровых преобразований на базе повсеместного применения ИКТ для экономического и социального развития страны. Об этом свидетельствует, в частности, проведение Президентом России Владимиром Путиным 10 июня, на фоне растущего кризиса, связанного с пандемией, совещания по вопросам развития информационно-коммуникационных технологий и связи. В этом событии представляется важным также и то, что едва ли не впервые на таком уровне драйвер экономического и социального прогресса - ИКТ и его коммуникационная составляющая - публично названы своими именами, а обсуждение, итоговый документ вышли, наконец, за пределы пресловутой "отрасли информационных технологий".

Совещание было весьма представительным. В нем участвовали председатель Правительства и руководитель Администрации Президента РФ со своими первыми заместителями, министры экономического развития, финансов, цифрового развития, связи и массовых коммуникаций, замминистра промышленности и торговли, губернатор Московской области - руководитель рабочей группы Государственного совета по направлению "Коммуникации, связь, цифровая экономика". А также руководители ПАО "Сбербанк России", ГК "Яндекс", "большой четверки" федеральных операторов связи, ряда ИТ-компаний.

В своем выступлении Президент подчеркнул роль и значимость отрасли (электросвязи/ИКТ), которые особенно ярко проявились в обстановке вынужденных ограничений, связанных с эпидемией. Государству нужно было максимально быстро реализовать решения по поддержке населения и экономики.

"Мы, еще раз хочу сказать, вместе смогли это сделать с помощью современных информационных технологий, инфраструктуры, которая создавалась на протяжении многих лет общими усилиями государства, бизнеса, инновационных команд", - сказал он.

Президент поблагодарил российские телекоммуникационные компании, профильных 
специалистов, которые в условиях возросшей нагрузки обеспечили непрерывную работу и высокий уровень востребованных сервисов. Ну и традиционно им была отмечена необходимость создания условий для ускоренной разработки и внедрения отечественных информационных технологий, трудности, с которыми сейчас столкнулась как сама отрасль, так и экономика в целом, включая вынужденное снижение расходов реального сектора на инновации, на ПО и сопутствующие услуги. В этой связи Правительству и регионам было предложено уделить самое пристальное внимание мерам поддержки спроса на продукцию наших IT-компаний.

Содержание объемного вступительного доклада президента некоммерческого партнерства разработчиков программного обеспечения РУССОФТ Валентина Макарова, последующих выступлений участников совещания было ограничено ИТ и проблемами бизнеса в этой сфере. О телекомму никациях говорил только генеральный директор ПАО "Ростелеком" Михаил Осеевский. Он отметил, что уже в начале апреля трафик в российском сегменте интернета вырос на 20-25\%. Пришлось масштабно увеличить пропускную способность магистральных линий и линий доступа, для того чтобы обеспечить такую потребность в первую очередь для жителей страны. Каким образом это удалось сделать он не пояснил. В целом М.Осеевский считает, что отрасль (в этот раз телекоммуникацион ная) адекватно ответила на вызовы и дала возможность людям с минимальными потерями пройти через эти испытания.

По результатам состоявшегося обсуждения в начале июля Президент утвердил итоговый доку мент: "Перечень поручений по итогам состоявшегося 10 июня 2020 года совещания по вопросу развития информационно-коммуникационных технологий и связи" (Пр-1068).

Документ содержит перечень из 11 поручений Правительству Российской Федерации "проработать вопросы" и одно - Государственной Думе ФС Российской Федерации, которой рекомендовано обеспечить совместно с Правительством РФ принятие федерального закона "Об экспериментальных правовых режимах в сфере цифровых инноваций в Российской Федерации". Срок выполнения всех поручений - 3 августа 2020 года.

С телекоммуникациями прямо связаны два из 12 поручений, и оба они относятся к актуальным, но частным случаям организации "последней мили":

- п. 1. 3) - обеспечению недискриминационного доступа операторов связи к инфраструктуре многоквартирных жилых домов для размещения сетей и средств электросвязи в целях повышения конкуренции и расширения предложения операторов связи. Заметим, что этот вопрос в такой же редакции стал актуальным еще в середине 90-х годов прошлого века, с появлением частных операторов электросвязи, кабельного телевидения (КТВ) и пережил много безуспешных попыток решения;

- п. 1. и) - включению в строительные нормы и правила условий об обязательном оснащении строящихся, реконструируемых или подлежащих капитальному ремонту многоквартирных жилых домов современной инфраструктурой широкополосного доступа к информационно-телекоммуникационной сети "Интернет".

Заметим, что последнее поручение непосредственно связано с п. 1. 3), поскольку невозможно предоставить доступ к тому, чего еще нет. Но, как свидетельствует многолетний опыт, проблема не может сводиться только к интернету, которую, кстати, в Москве операторы давно решили. Необходимо общее решение для всех случаев использования электросвязи в ЖКХ, то есть именно создание инфраструктуры коммуникаций в многоквартирных жилых домах, позволяющей также подключения сетей КТВ (или домовых антенн), систем охраны, оповещения, домофонов, лифтового хозяйства, разного рода датчиков и систем в составе технологий умного города, других.

Еще два важных и своевременных поручения общего характера можно и должно отнести и к телекоммуникациям:

- п. 1. б) совершенствование нормативно-правовой базы для обеспечения устойчивого развития и конкурентоспособности организаций отрасли информационно-коммуникационных технологий, в том числе с учетом ведущих международных практик;

- 1. е) расширения мер поддержки инновационных технологических стартапов в сфере информационно-коммуникационных технологий, предоставляемых институтами развития.

Жаль конечно, что Правительству РФ поручается всего лишь "проработать вопросы", что наверняка было успешно выполнено в установленный срок. Но актуальность и повестка дня совещания несомненно имеют большое значение для отрасли, во всех ее толкованиях. Надеемся, что результатом проработки станут решения, эффективные для развития цифровой инфраструктуры и успешного послекризисного восстановления. 
КСС-КОНТАКТ

компания

\&5 $+7(495) 648 \cdot 75 \cdot 45$ intogik-kn 9 www.k-knu

\section{Новая линейка оптических муфт От КСС-КОНТАКТ.}

Для сращивания и защиты места "сварки" оптического кабеля, как правило, применяются оптические муфты. Муфты обеспечивают защиту мест соединения кабеля от внешнего воздействия окружающей среды, позволяют обеспечить транзит кабеля, подвести кабель к абоненту и т.д.

Чтобы расширить возможности муфты, унифицировать ее̄ использование, оптимизировать процесс и спосо6 инсталляции муфты, а также иметь возможность использовать одну и ту же муфту для решения сопряженных задач на месте, компания КСС-КОНТАКТ задалась целью разработать такие оптические муфты, которые смогут универсально решать массу сопряженных задач. А также обеспечат решение таких амбициозных потребностей провайдеров и операторов связи, как возможность "разварить" 96 оптических волокон на одной сплайс-кассете в муфте малого размера, обеспечат возможность установки PLC-сплиттеров, УСМ-модулей, адаптеров и сопряженных компонентов ВОЛС сразу в этой же муфте. Компания КСС-КОНТАКТ разработала и уже запустила в продажу серию оптических муфт ОМТ-КС разных размеров, которые не просто решают задачу обеспечения надежного и долговечного узла защиты места соединения оптического кабеля, но и предполагают быстрое решения дальнейшего подключения абонентов к сети без замены муфты и внесения координальных изменений в готовую линию связи.

\section{Абонентские терминалы. Дроп-мУфтЫ От КСС-КОНТАКТ.}

Абонентские терминалы выполняют фактически ту же функцию, что и оптические муфты, но имеют ряд существенных преимуществ при строительстве сетей PON в частном секторе и в районах малоэтажной застройки. Компания КСС-КОНТАКТ предлагает своё решение на примере 2-х позиций: модель Т8.1 и Т8.2.

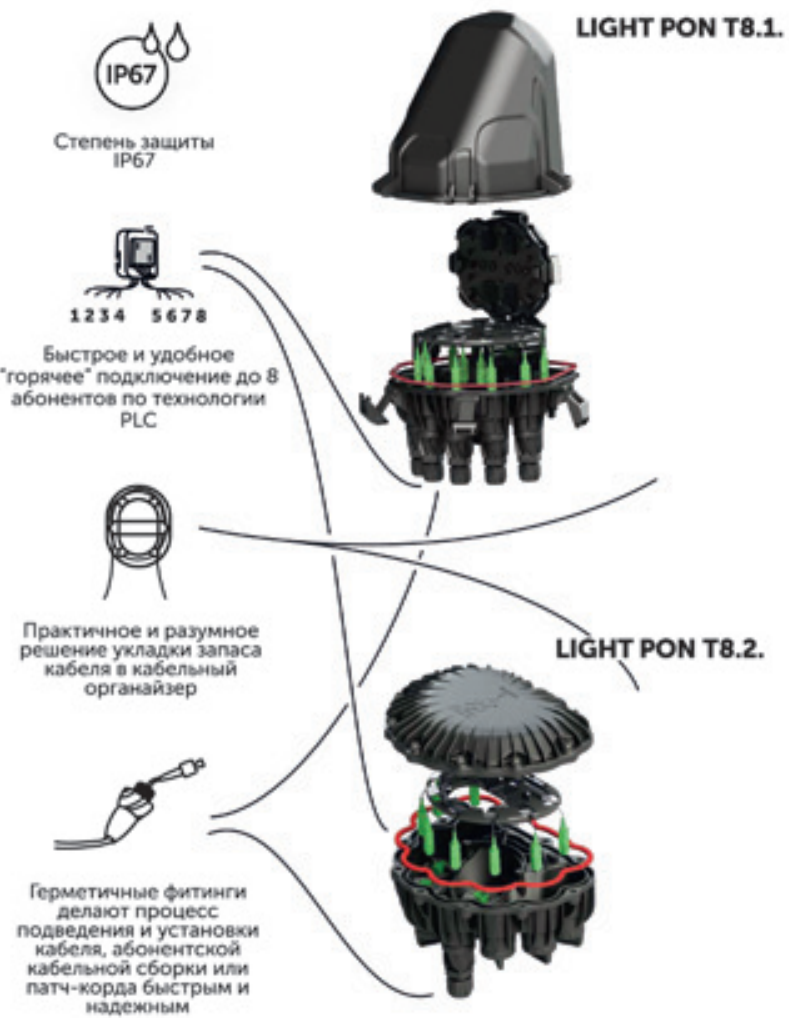

\section{OMT-KC M96.}

Серия M

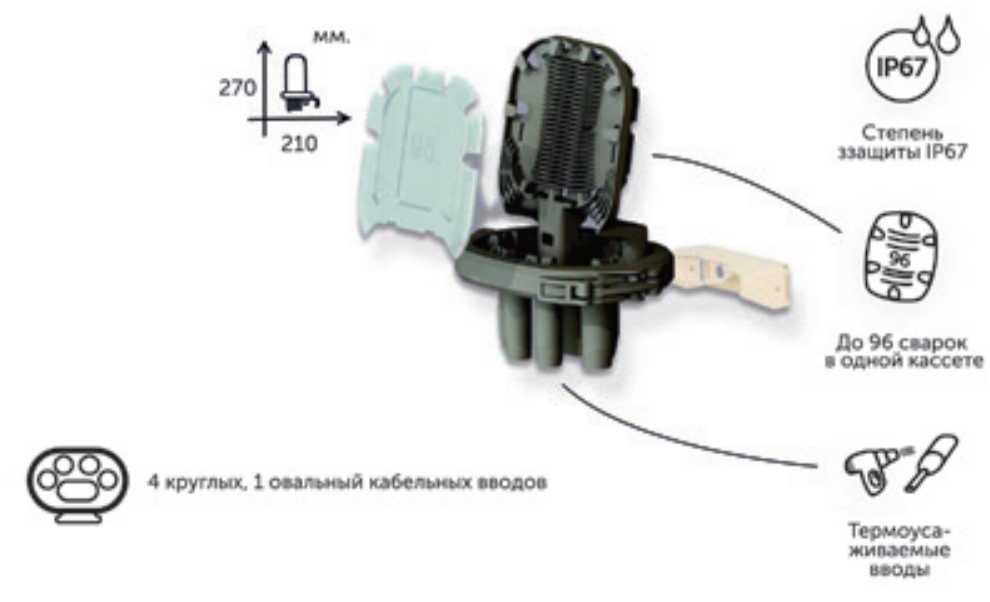

OMT-KC L 288.

Серия L
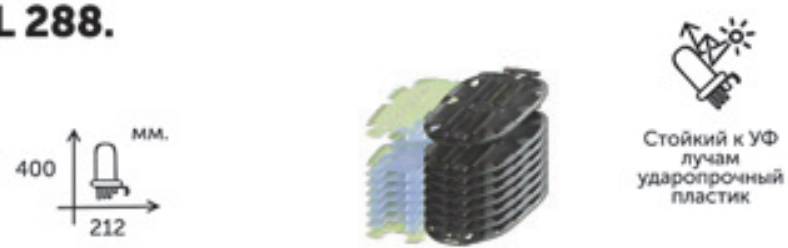

OMT-KC XL 288. Серия XL

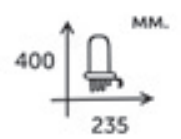

4 кругпшх, 1 овальный кабельных аводов
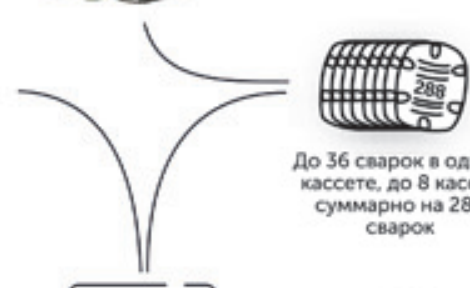

До 36 сварок в одно caccete, AO 8 кaccer суммарно на 288 сварок

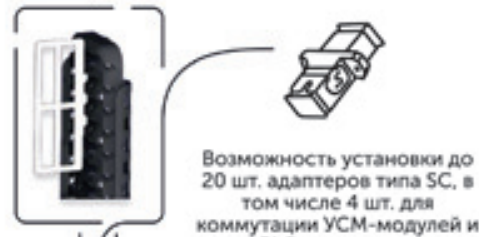

коммутаини 4 шт. Али PLC сплиттеров
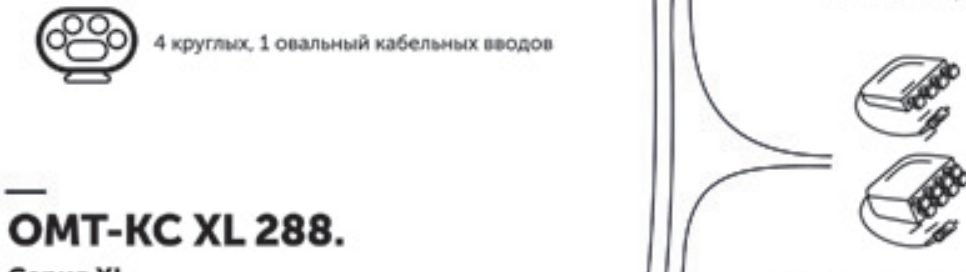

омможность установхи до 4 шт. УСМ-модулей $1 \times 8$ или $1 \times 4$ 